\title{
A Fuzzy Multiobjective Model for Supplier Selection under Considering Stochastic Demand in a Supply Chain
}

\author{
Wei Pan, Fengxia Wang, Ying Guo, and Shan Liu \\ Economics and Management School of Wuhan University, Wuhan 430072, China \\ Correspondence should be addressed to Wei Pan; mrpanwei2000@163.com and Shan Liu; shan.l.china@gmail.com
}

Received 3 March 2014; Revised 3 October 2014; Accepted 3 October 2014

Academic Editor: Tsung-Chih Lin

Copyright (C) 2015 Wei Pan et al. This is an open access article distributed under the Creative Commons Attribution License, which permits unrestricted use, distribution, and reproduction in any medium, provided the original work is properly cited.

\begin{abstract}
With the development of market competition, company faces more and more pressures. Meanwhile, procurement has a vital effect on achieving competitive advantages in a supply chain. Selecting the appropriate suppliers is one of the most important sections in purchase management. However, in real situation, supplier selection is a multiple objective problem about different items with vagueness and randomness of the data. It is very complex. Hence, research about supplier selection is relatively scarce under considering multiple items, discount price, and fuzzy and stochastic information. In our paper, we develop a fuzzy multiobjective supplier selection model for overcoming uncertainty and multiple items. Stochastic demand, fuzzy objectives, and weights are simultaneously applied to help the managers to select the suitable suppliers about different items. For illustration purpose, a numerical example is presented to verify the effectiveness of the proposed model.
\end{abstract}

\section{Introduction}

In today's globally competitive environment, companies are facing more and more pressures and challenges. In most industries the cost of raw materials and component parts constitutes the main cost of a product; particularly in some cases it can account for up to 70\% [1]. In some high technology firms, purchased materials and services represent up to $80 \%$ of total product cost [2]. In this situation, supplier selection plays a key role in reducing purchasing costs, improving competition ability, and so on.

For supplier selection problem, information is usually uncertainty and imprecision [3]. At the time of making decisions, the value of many objectives and constraints is expressed in vague terms such as "very high in quality" or "low in cost," while some variables are stochastic. Hence, manager must consider the vague data and stochastic information for selecting suitable suppliers from many potential candidates. In this situation, the theory of fuzzy sets and stochastic approach are two of the best methods for handling supplier selection problem.

Hence, this creates a great challenge for the scholars to find an efficient solution to dealing with fuzzy data and stochastic information $[4,5]$. The general strategy is to defuzzify and/or derandomize fuzzy random variables to convert the problem into a deterministic problem. The first direction is to perform the conversions (defuzzify, derandomize) in a sequential manner $[6,7]$. The second way is to perform both actions at the same time by calculating the expected value of fuzzy random variables [8-11]. The obtained LP/NLP from Luhandjula approaches [6] can be solved directly by the traditional optimization packages such as LINGO, CPLEX.

Meanwhile, the supplier selection is a multiobjective decision problem about different items, which is affected by several conflicting factors including cost, service, and quality. Moreover, multiple objectives usually are unequally important. Consequently a purchasing manager must analyze the trade-off among the several objectives under different items. According to uncertain information and different items, some scholars have published many papers. Kumar et al. [12] proposed fuzzy goal programming for supplier selection problem with multiple sourcing that includes three primary goals: minimizing the net cost, minimizing the net rejections, and minimizing the net late deliveries subject to realistic constraints regarding buyer's demand, vendors' capacity. In 
their model, Zimmermann's weightless technique is used in which there is no difference between objective functions. Amid et al. [13] presented fuzzy multiobjective linear model. In their model, objectives are vague but constraints are deterministic and weight is known. Amid et al. [14] constructed a fuzzy multiobjective supplier model under price break. In this model, constraints and weight also are deterministic. Wu et al. [15] proposed a fuzzy multiobjective programming model to decide on supplier selection taking risk factors into consideration. Ozkok and Tiryaki [16] established a compensatory fuzzy approach to solve multiobjective linear supplier selection problem with multiple items by using cost, service, and quality as objectives. Lin [17] study proposes to adopt the fuzzy analytic network process approach first to identify top suppliers by considering the effects of interdependence among selection criteria and to handle inconsistent and uncertain judgments. Nazari-Shirkouhi et al. [18] solve a supplier selection problem under multiprice level and multiproduct using interactive two-phase fuzzy multiobjective linear programming model. Kilic [19] developed an integrated approach including fuzzy technique for selecting the best supplier in a multi-item/multisupplier environment. Choudhary and Shankar [20] address a problem in which a storage space constrained buyer procures a single product in multiple periods from multiple suppliers. Pan et al. [21] constructed a fuzzy multiobjective model for provider selection. They used linear/nonlinear matrix inequality for solving this problem.

However, in real situation, objectives, constraints, and weights usually are uncertain. The manager cannot precisely give relative information in supplier selection. But these previous researches do not simultaneously consider these conditions. Thus, for constructing more practical and meaningful solution to the supplier selection problem, we present a new fuzzy multiobjective supplier selection model under considering fuzzy objectives, constraints, weights, and stochastic demand in a supply chain.

This paper differs from past studies in that it includes five features as follows:

(1) according to uncertain information, weight is vague besides fuzzy objectives and constraints;

(2) based on real situation, stochastic demand is assumed;

(3) for extending application scope, we establish a general model that includes line and nonline form;

(4) under considering practical condition, we construct a supplier selection model about multiple items;

(5) unit price is affected by quantity.

The main motivation of this study is, under considering uncertain information and multiple items, how to optimize supplier selection in supply chain for the company. Furthermore, in this research, a numerical example is presented to illustrate the validation of the proposed model because this problem is complex and difficult. Through a number example case, we prove that this supplier selection model is feasible.

The rest of this paper is organized as follows. In Section 2, a brief description of fuzzy set theory (FST) is first presented.

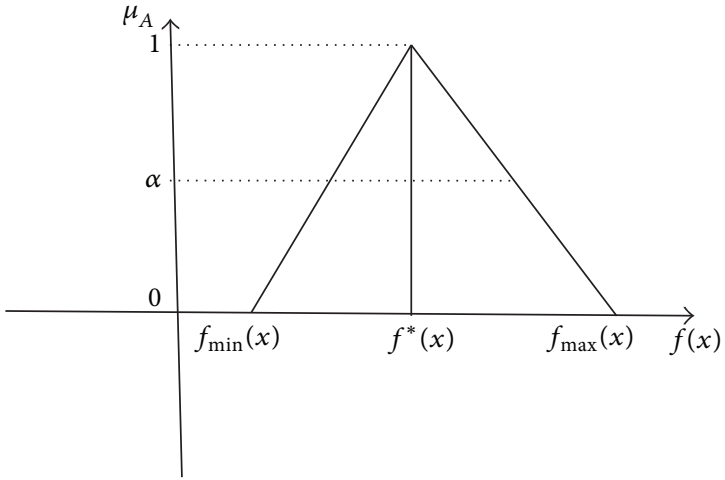

FIGURE 1: The different membership functions.

In Section 3, a fuzzy multiobjective model is constructed under considering different items, discount price, stochastic demand, fuzzy objectives, constrains, and weights. For solving this problem, an algorithm is presented. In Section 4, we present a numerical example and explain the outcomes. Finally, the results are drawn in Section 5.

\section{Fuzzy Set Theory}

Fuzzy set theory (FST), first proposed by Zadeh [22], is one of the best tools to handle the imprecision or vagueness. Under many conditions, crisp data are inadequate to model real world situations, since human judgments are often vague and cannot be estimated by an exact numerical value. To deal with vagueness of human thought, Zadeh [22] first introduced the fuzzy logic theory, which was oriented to the rationality of uncertainty due to imprecision or vagueness. Therefore a major contribution of FST (fuzzy set theory) is its capability for representing vagueness.

In this section, some basic definitions of fuzzy sets, fuzzy numbers, and linguistic variables are reviewed from Buckley [23], Kaufmann and Gupta [24], Negi [25], and Zadeh [26]. The basic definitions and notations below will be used throughout this paper until otherwise stated.

Definition 1. Let $X$ be a universe of discourse; $A$ is a fuzzy subset of $X$ if, for all $x \in X$, there is a number $\mu_{A} \in[0,1]$ assigned to represent the membership of $x$ to $A$, and it is called the membership function of $A$ as in Figure 1.

Definition 2. When the (crisp) set of elements belong to the fuzzy set $A$, the degree of its membership function exceeds the level $\alpha: A_{\alpha}=\left[x \in X \mid \mu_{A} \geq \alpha\right]$ as in Figure 1 .

Definition 3. $f(x)=\left(f_{1}, \ldots, f_{2}\right)$ are the objective functions and $G(x)$ are the system constraints. $f_{i}^{*}(x), i=1, \ldots, m$, is the optimal goal value to the objective as in Figure 1.

Definition 4 (fuzzy decision). A fuzzy decision is defined in an analogy to nonfuzzy environments "as the selection of activities which simultaneously satisfy objective functions and constraints." In fuzzy set theory the intersection of sets normally corresponds to the logical "and." The "decision" in a 
fuzzy environment can therefore be viewed as the intersection of fuzzy constraints and fuzzy objective functions [27]. In the multiobjective fuzzy decision, the objectives and constraints are usually not equally important and have different weights [27-29]. In many cases, the decision-maker can not precisely set his relative weights. Thus, the weights are assumed to be fuzzy numbers with either trapezoidal or triangular membership functions. The $\alpha$-cut approach is utilized within the fuzzy weighted model.

\section{A Multiobjective Fuzzy Supplier Selection Model under Considering Different Items and Uncertain Information}

3.1. A Multiobjective Stochastic Supplier Selection Model about Different Item. A general multiobjective supplier selection model can be stated as follows:

$$
\begin{gathered}
\min f(1), \ldots, f(k) \\
\max f(k+1), \ldots, f(q)
\end{gathered}
$$

and constraints:

$$
\begin{array}{r}
x \in g_{i j}(x), \quad g_{i j}(x)=\left\{\operatorname{Pr}\left(\sum_{t=1}^{n} a_{i t j} x_{t j} \geq b_{i j}\right) \geq \beta_{i j},\right. \\
i=1, \ldots, m, j=1, \ldots, p\},
\end{array}
$$

where $f(1), \ldots, f(k)$ are the negative objectives or criterialike cost, lead time, and so forth. $f(k+1), \ldots, f(q)$ are the positive objectives or criteria such as quality and service, $X_{t}$ are nonnegative decision variables, and $b_{i j}$ are independent continuous random variables with given distributions in the $i$ th constraint about the $j$ th item, while $a_{i t j}$ represents the coefficient of the $t$ th decision variable and $\beta_{i j}$ is the $i$ th preassigned probability level for the $j$ th item, $0<\beta_{i j} \leq 1$.

\subsection{A Fuzzy Multiobjective Supplier Selection Model under} Considering Many Items and Uncertain Information. Generally, managers do not have exact and complete information related to objective, constraints, and weights. A fuzzy multiobjective model is developed to deal with supplier selection problem in this condition. In a fuzzy multiobjective supplier selection model, the sign indicates the fuzzy environment. The symbol $z$ in the objectives and constraints indicates fuzziness of $\geq$, that is, approximately greater than or equal to; in contrast $\lesssim$ has linguistic interpretation "essentially smaller than or equal to."

A general multiobjective fuzzy supplier selection model can be expressed as follows:

$$
\begin{gathered}
f(d) \lesssim \tilde{f}_{d} \quad d=1, \ldots, k, \\
f(e) \gtrsim \tilde{f}_{e} \quad e=k+1, \ldots, q, \\
\operatorname{Pr}\left(\sum_{t=1}^{n} a_{i t j} x_{t j} \gtrsim b_{i j}\right) \gtrsim \beta_{i j}, \quad i=1, \ldots, m, j=1, \ldots, p .
\end{gathered}
$$

Thus, by incorporating $c_{i t j}$ and $\sigma_{i j}$, where $c_{i t j}>0$ and $0<$ $\sigma_{i j}<\beta_{i j}$, as predetermined values set by the decision-maker, then the satisfaction constraints of the decision-maker can be stated as follows.

The decision-maker is fully satisfied if

$$
\operatorname{Pr}\left(\sum_{t=1}^{n} a_{i t j} x_{t j} \geq b_{i j}\right) \geq \beta_{i j} .
$$

The decision-maker is almost satisfied if

$$
\begin{gathered}
\sigma_{i j}<\operatorname{Pr}\left(\sum_{t=1}^{n} a_{i t j} x_{t j} \geq b_{i j}\right)<\beta_{i j}, \\
\operatorname{Pr}\left(\sum_{t=1}^{n}\left(a_{i t j}+c_{i t j} x_{t j}\right) \geq b_{i j}\right)>\beta_{i j} .
\end{gathered}
$$

The decision-maker is not satisfied if

$$
\begin{gathered}
\operatorname{Pr}\left(\sum_{t=1}^{n} a_{i t j} x_{t j} \geq b_{i j}\right) \leq \sigma_{i j} \text { or } \\
\operatorname{Pr}\left(\sum_{t=1}^{n}\left(a_{i t j}+c_{i t j} x_{t j}\right) \geq b_{i j}\right) \leq \beta_{i j} .
\end{gathered}
$$

Then, the equivalent deterministic constraints for (4)-(6), respectively, are

$$
\begin{gathered}
\sum_{t=1}^{n} a_{i t j} x_{t j} \geq F_{i j}^{-1}\left(\beta_{i j}\right), \\
F_{i j}^{-1}\left(\sigma_{i j}\right)<\sum_{t=1}^{n} a_{i t j} x_{t j}<F_{i j}^{-1}\left(\beta_{i j}\right), \\
F_{i}^{-1}\left(\beta_{i j}\right)<\sum_{t=1}^{n}\left(a_{i t j}+c_{i t j}\right) x_{t j}, \\
\sum_{t=1}^{n} a_{i t j} x_{t j} \leq F_{i j}^{-1}\left(\sigma_{i j}\right) \text { or } \\
\sum_{t=1}^{n}\left(a_{i t j}+c_{i t j}\right) x_{t j} \leq F_{i j}^{-1}\left(\beta_{i j}\right),
\end{gathered}
$$

where $F_{i j}^{-1}(\cdot)$ is the inverse of the cumulative distribution function of the random variable $b_{i j}$.

Using the Bellman-Zadeh approach, the fuzzy set objective functions $f_{r}$ and constraints $g_{i}$ are defined by

$$
\begin{array}{r}
f_{r}=\left\{x, \mu_{f_{r}}(x)\right\}, \quad g_{i}=\left\{x, \mu_{g_{i}}(x)\right\}, \\
x \in L, \quad r=1, \ldots, q, \quad i=1, \ldots, m,
\end{array}
$$

where $\mu_{f_{r}}(x), \mu_{g_{i}}(x) \mid x \rightarrow[0,1]$ are the membership function of objectives and constraints and $\mu_{f_{r}}(x), \mu_{g_{i}}(x)$ are the degree of membership at which $x$ belongs to objectives and constraints. The fuzzy set objectives and constraints are thus uniquely determined by its membership function $\mu_{f_{r}}(x), \mu_{g_{i}}(x)$ and the range of membership function is a 

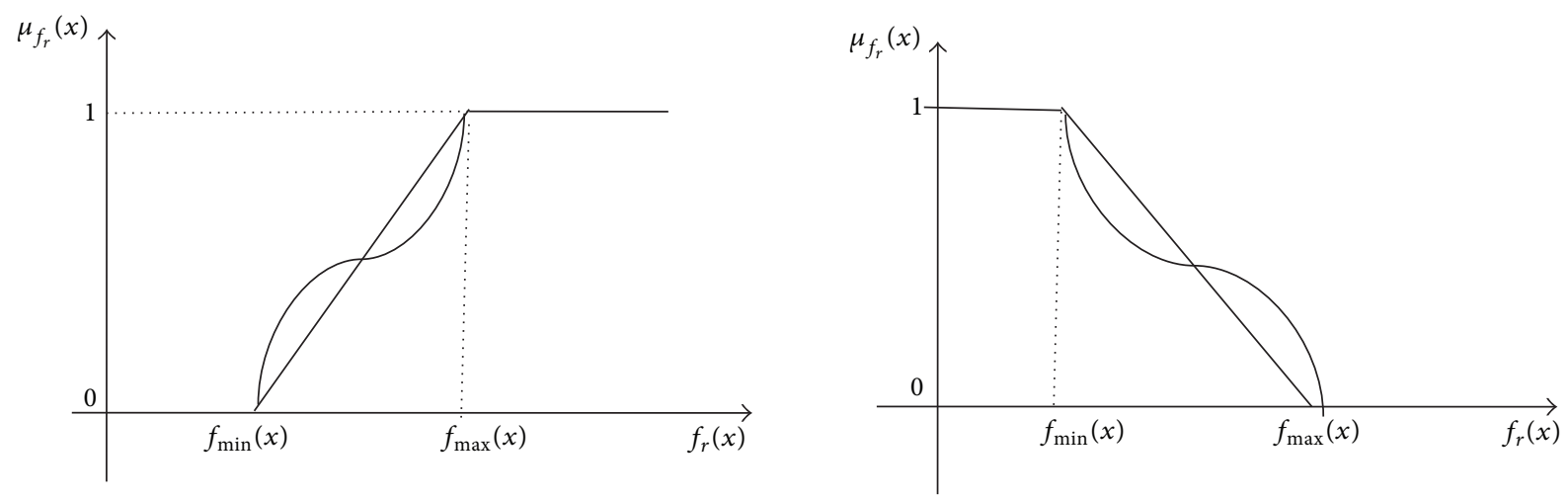

FIgure 2: The different membership functions.

subset of the nonnegative real numbers whose value is finite and usually finds a place in the interval $[0,1]$.

Using (8), it is possible to obtain the solution proving the maximum degree

$$
\begin{gathered}
\max \mu_{D}(x)=\max _{x \in L}\left\{\min _{r=1, \ldots, q} \mu_{f_{r}}(x), \min _{i=1, \ldots, m} \mu_{g_{i}}(x)\right\}, \\
x^{0}=\arg \max _{x \in L}\left\{\min _{r=1, \ldots, q} \mu_{f_{r}}(x), \mu_{g_{i}}(x)\right\} .
\end{gathered}
$$

To obtain (9), it is necessary to build membership functions $\mu_{f_{r}}(x)$ and $\mu_{g_{i}}(x), r=1, \ldots, q, i=1, \ldots, m$, by the corresponding $f_{r}(x), g_{i}(x), x \in L, r=1, \ldots, q, i=1, \ldots, m$. This is satisfied by the use of the membership functions

$$
\mu_{f_{r}}(x)=\left\{\begin{array}{l}
1, \\
f_{r}(x) \geq \max _{x \in L} f_{r}(x), \\
{\left[\frac{f_{r}(x)-\min _{x \in L} f_{r}(x)}{\max _{x \in L} f_{r}(x)-\min _{x \in L} f_{r}(x)}\right]^{\lambda_{r}},} \\
0, \\
\min _{r \in L} f_{r}(x) \leq f_{r}(x) \leq \max _{x \in L} f_{r}(x), \\
\min _{x \in L} f_{r}(x)
\end{array}\right.
$$

for maximized objective functions or by the use of the membership functions

$$
\mu_{f_{r}}(x)=\left\{\begin{array}{l}
1, \\
f_{r}(x) \leq \min _{x \in L} f_{r}(x), \\
{\left[\frac{\max _{x \in L} f_{r}(x)-f_{r}(x)}{\max _{x \in L} f_{r}(x)-\min _{x \in L} f_{r}(x)}\right]^{\lambda_{r}},} \\
\min _{x \in L} f_{r}(x) \leq f_{r}(x) \leq \max _{x \in L} f_{r}(x), \\
f_{r}(x) \geq \max _{x \in L} f_{r}(x)
\end{array}\right.
$$

for minimized objective functions as in Figure 2.
The construction of (10) or (11) demands solving the following problems:

$$
\begin{aligned}
& f_{r}(x) \longrightarrow \min _{x \in L} f_{r}(x), \\
& f_{r}(x) \longrightarrow \max _{x \in L} f_{r}(x) ;
\end{aligned}
$$

$\min _{x \in L} f_{r}(x), \max _{x \in L} f_{r}(x)$ are obtained through solving the multiobjective problem as a single objective using, each time, only one objective and $x \in L$ means that solutions must satisfy constraints. Since, for every objective function $f_{r}(x)$, its value changes from $\min _{x \in L} f_{r}(x)$ to $\max _{x \in L} f_{r}(x)$, it may be considered as a fuzzy number with the membership function $\mu_{f_{r}}(x)$ as shown in (10) or (11):

$$
\mu_{g_{i j}}(x)=\left\{\begin{array}{l}
1, \\
g_{i j}(x) \geq F_{i j}^{-1}\left(\beta_{i j}\right), \\
\min \left\{k_{i j}(x), h_{i j}(x)\right\}, \\
F_{i j}^{-1}\left(\sigma_{i j}\right)<\sum_{t=1}^{n} a_{i t j} x_{t j}<F_{i j}^{-1}\left(\beta_{i j}\right) \\
\quad<\sum_{t=1}^{n}\left(a_{i t j}+c_{i t j}\right) x_{t j}, \\
0, \quad{ }_{i j}^{n}, \sum_{t=1}^{n} a_{i t j} x_{t j} \leq F_{i j}^{-1}\left(\sigma_{i j}\right) \text { or } \\
g_{i j}(x) \geq b_{i j}+d_{i j}, \\
\sum_{t=1}^{n}\left(a_{i t j}+c_{i t j}\right) x_{t j} \leq F_{i j}^{-1}\left(\beta_{i j}\right),
\end{array}\right.
$$

where $k_{i j}(x)$ and $h_{i j}(x)$ are defined by

$$
\begin{gathered}
k_{i j}(x)=\left[\frac{\left(\sum_{t=1}^{n} a_{i t j} x_{t j}-F_{i j}^{-1}\left(\sigma_{i j}\right)\right)}{\left(F_{i j}^{-1}\left(\beta_{i j}\right)-F_{i j}^{-1}\left(\sigma_{i j}\right)\right)}\right]^{\lambda_{i j}^{\prime}}, \\
h_{i j}(x)=\left[\frac{\left(\sum_{t=1}^{n}\left(a_{i t j}+c_{i t j}\right) x_{t j}-F_{i j}^{-1}\left(\beta_{i j}\right)\right)}{\sum_{t=1}^{n} c_{i t j} x_{t j}}\right]^{\lambda_{i}^{\prime}}, \\
\sum_{t=1}^{n} x_{t j} \neq 0 .
\end{gathered}
$$


On the other hand, if

$$
\begin{gathered}
\operatorname{Pr}\left(\sum_{i=1}^{m} a_{i t j} x_{t j} \lesssim b_{i j}\right) \gtrsim \beta_{i j}, \\
k_{i j}(x)=\left[\frac{\left(F_{i j}^{-1}\left(1-\sigma_{i j}\right)-\sum_{t=1}^{n} a_{i t j} x_{t j}\right)}{\left(F_{i j}^{-1}\left(1-\sigma_{i j}\right)-F_{i j}^{-1}\left(1-\beta_{i j}\right)\right)}\right]^{\lambda_{i j}^{\prime}}, \\
h_{i j}(x)=\left[\frac{\left(F_{i j}^{-1}\left(1-\beta_{i j}\right)-\sum_{t=1}^{n}\left(a_{i t j}-c_{i t j}\right) x_{t j}\right)}{\sum_{t=1}^{n} c_{i t j} x_{t j}}\right]^{\lambda_{i j}^{\prime}}, \\
\sum_{t=1}^{n} x_{t} \neq 0
\end{gathered}
$$

(13) are membership functions of fuzzy values of linguistic variables which reflect constraints of qualitative character about the $j$ th item. In (10), (11), (14), (16), and (17), $\lambda_{r}, \lambda_{i j}^{\prime}$ are important factors for the objectives and constraints about the jth item.

3.3. Decision Making Processes. First, the max-min operator is discussed, which was used by Zimmermann [28, 30] for fuzzy multiobjective problems. Then, the convex (weighted additive) operator is stated that enables the DMs to assign different weights to various criteria.

In fuzzy programming modeling, using Zimmermann's approach, a fuzzy solution is given by the intersection of all the fuzzy sets representing either fuzzy objective or fuzzy constraints. The fuzzy solution for all fuzzy objectives and fuzzy constraints may be given as

$$
\mu_{D}(x)=\left\{\left\{\bigcap_{r=1}^{q} \mu_{f_{r}}(x)\right\} \bigcap\left\{\bigcap_{i=1}^{m} \mu_{g_{i j}}(x)\right\}\right\}, \quad x \in L .
$$

The optimal solution $\left(x^{*}\right)$ is given by

$$
\mu_{D}\left(x^{*}\right)=\max \mu_{D}(x)
$$

where $\mu_{D}(x), \mu_{f_{r}}(x)$, and $\mu_{g_{i j}}(x)$ represent the membership functions of solution, objective functions, and constraints about the $j$ th item.

In practical situation, different objectives and constraints have unequal importance to managers; weights should be considered. The fuzzy weighted additive model can handle this problem, which is described as follows.

The weighted additive model is widely used in vectorobjective optimization problems; the basic concept is to use a single utility function to express the overall preference of DM to draw out the relative importance of criteria. In this case, multiplying each membership function of fuzzy goals by their corresponding weights and then adding the results together obtain a weighted utility function.
The fuzzy model proposed by Bellman and Zadeh [31], Sakawa [29] and the weighted additive model proposed by Tiwari et al. [32] are

$$
\begin{gathered}
\mu_{D}(x)=\sum_{j=1}^{q} w_{j} \eta+\sum_{j=q+1}^{q+m} w_{j} \kappa, \\
\sum_{r=1}^{q} w_{f_{r}}+\sum_{i=1}^{m} w_{g_{i j}}=1, \quad w_{f_{r}}, w_{g_{i j}} \geq 0,
\end{gathered}
$$

where $w_{f_{r}}$ and $w_{g_{i j}}$ are the weighting coefficients that present the relative importance among the fuzzy goals and fuzzy constraints about the $j$ th item:

$$
\begin{gathered}
\max \widetilde{w}_{f_{r}} \eta+\widetilde{w}_{g_{i j}} \kappa, \\
\eta \leq \mu_{f_{r}}(x), \\
\kappa \leq \mu_{g_{i j}}(x), \\
x_{t j} \in L .
\end{gathered}
$$

If $w_{s}$ denotes the fuzzy weight of the $j$ th objective or constraint, let $\widetilde{w}_{s}=\left\{\underline{w}_{s}, w_{s 1}, w_{s 2}, \bar{w}_{s}\right\}, s=1, \ldots, p+m$, be a trapezoidal fuzzy number or let $\widetilde{w}_{s}=\left\{\underline{w}_{s}, w_{s 0}, \bar{w}_{s}\right\}, s=$ $1, \ldots, p+m$ be a triangular fuzzy number. Then, by utilizing the $\alpha$-cut approach for $\widetilde{w}_{j}$, as trapezoidal fuzzy number, the suggested model can be represented in the form of weighted max-min deterministic-crisp nonlinear programming model, as follows:

$$
\max \sum_{j=1}^{q} w_{j} \eta_{j}+\sum_{j=q+1}^{q+m} w_{j} \kappa_{j}
$$

s.t.:

$$
\begin{gathered}
\eta_{r} \leq \mu_{f_{r}}(x), \\
\kappa_{i} \leq \mu_{g_{i}}(x), \\
\underline{w}_{s}(1-\alpha)+w_{s 1} \leq w_{s} \leq \bar{w}_{s}(1-\alpha)+w_{s 2}, \\
\sum_{s=1}^{m+q} w_{s}=\sum_{r=1}^{q} w_{f_{p}}+\sum_{i=1}^{m} w_{g_{i}}=1, \quad w_{f_{r}}, w_{g_{i}} \geq 0, \\
x_{t} \geq 0 .
\end{gathered}
$$

It should be noticed that $w_{s}, s=1,2, \ldots, m+p$, become decision variables, in addition to $\eta_{p}, \kappa_{i}$, and $x_{t}$. The crisp constraint set (25) is derived by applying the $\alpha$-cut approach to the trapezoidal membership functions of the fuzzy weights, where $\alpha$ is $\alpha \in(0,1]$ predetermined value $\alpha \in(0,1]$. Constraint (26) insures that the relative weights should add up to one. The decision-maker has to set the value of $\alpha$, carefully, to avoid infeasible solutions. Also, the fuzzy weights reflect the uncertain relative importance of the objectives, where the sum of the values of all fuzzy weights should be one, that is, $\sum_{s=1}^{m+q} w_{s}=1$, and the sum of the least values of all fuzzy weights should be less than one, that is, $\sum_{s=1}^{m+q} w_{s} \leq 1$. 
On the other hand, if $\widetilde{w_{s}}$, for any sth objective or constraints, is considered as triangular fuzzy number, then $w_{s 1}$ and $w_{s 2}$ should be replaced by $w_{s 0}$, for the sth objective or constraint.

3.3.1. The Algorithm. For supplier selection problem, a multiobjective fuzzy model about different items is presented as follows.

Step 1. According to multiple items, the objectives and constraints, we construct a supplier selection model in (1)(2).

Step 2. Under considering uncertain information, we provide the corresponding fuzzy multiple objectives model by (3).

Step 3. By $c_{i t j}$ and $\sigma_{i j}$, where $c_{i t j}>0$ and $0<\sigma_{i j}<$ $\beta_{i j}$, as predetermined values set by the decision-maker, the satisfaction constraints of the decision-maker can be expressed as (4)-(7).

Step 4. By solving every objective maximum and minimum value, we defined the objective membership function in (10) or (11).

Step 5. About the probabilistic fuzzy goal constraints, the membership function is defined by (13).

Step 6. From considering practical condition, we establish random variable $b_{i j}$ distribution, fuzzy objectives, constraints, and weights (a trapezoidal/triangular fuzzy number).

Step 7. According to actual data, we construct relative factor value.

Step 8. Using Zimmermann's method, a solution is provided by (18) and (20).

Step 9. By the membership function, we establish a multiobjective supplier selection model according to (21).

Step 10. From Step 7, we construct the equivalent crisp model on (22)-(27).

Step 11. Obtain the optimal solution vector $x^{*}$.

\section{Numerical Example}

In this section, a numerical example is presented to illustrate the above algorithm.

\subsection{Assumptions}

(i) Two items are purchased from two suppliers;

(ii) demands about different items are normally distributed variable with mean of 40 and 50 and variance of 49 and 64;

(iii) supplier capacities about every item are limited;
TABLE 1: Collected data for numerical example.

\begin{tabular}{|c|c|c|c|c|c|c|}
\hline Supplier & Kind & Quantity & Price & Quality & Service & Capacity \\
\hline \multirow{6}{*}{1} & & $X \leqslant 20$ & 8 & & & \\
\hline & Item 1 & $20<X \leqslant 40$ & 6 & 0.8 & 0.7 & 80 \\
\hline & & $40<X$ & 5 & & & \\
\hline & & $X \leqslant 25$ & 12 & & & \\
\hline & Item 2 & $25<X \leqslant 45$ & 11 & 0.8 & 0.8 & 100 \\
\hline & & $45<X$ & 9 & & & \\
\hline \multirow{6}{*}{2} & & $X \leqslant 25$ & 7 & & & \\
\hline & Item 1 & $25<X \leqslant 35$ & 6 & 0.9 & 0.9 & 90 \\
\hline & & $35<X$ & 4 & & & \\
\hline & & $X \leqslant 20$ & 13 & & & \\
\hline & Item 2 & $20<X \leqslant 50$ & 10 & 0.9 & 0.7 & 80 \\
\hline & & $50<X$ & 9 & & & \\
\hline \multicolumn{7}{|c|}{ TABLE 2: Weight values. } \\
\hline$\widetilde{\widetilde{w}}_{1}$ & 0.2 & & 0.3 & & 0.4 & 0.5 \\
\hline$\widetilde{w}_{2}$ & 0.1 & & 0.2 & & 0.25 & 0.4 \\
\hline$\widetilde{w}_{3}$ & 0.2 & & 0.25 & & 0.3 & 0.4 \\
\hline$\widetilde{w}_{4}$ & 0.1 & & 0.3 & & 0.4 & 0.5 \\
\hline
\end{tabular}

(iv) objectives include cost $\left(f_{1}\right)$, quality $\left(f_{2}\right)$, and service $\left(f_{3}\right)$; constraint demand is almost satisfied;

(v) unit price is affected by quantity.

This example consists of three objectives and one probabilistic fuzzy constraint, relative data come from Tables 1 and 2, as follows.

Item 1:

$$
\begin{gathered}
\tilde{f}_{1}=\left[\begin{array}{l}
8 \\
6 \\
5
\end{array}\right] x_{11}+\left[\begin{array}{l}
7 \\
6 \\
4
\end{array}\right] x_{21} \widetilde{\leq} f_{1}^{0}, \\
\tilde{f}_{2}=0.8 x_{11}+0.9 x_{21} \tilde{\geq} f_{2}^{0}, \\
\tilde{f}_{3}=0.7 x_{11}+0.9 x_{21} \tilde{\leq} f_{3}^{0}, \\
\operatorname{Pr}\left(x_{11}+x_{21} \geq b_{1}\right) \gtrsim 0.8 ;
\end{gathered}
$$

Item 2:

$$
\begin{gathered}
\tilde{f}_{1}=\left[\begin{array}{c}
12 \\
11 \\
9
\end{array}\right] x_{12}+\left[\begin{array}{c}
13 \\
10 \\
9
\end{array}\right] x_{22} \tilde{\leq} f_{1}^{0}, \\
\tilde{f}_{2}=0.8 x_{12}+0.8 x_{22} \geq f_{2}^{0}, \\
\tilde{f}_{3}=0.9 x_{12}+0.7 x_{22} \tilde{\leq} f_{3}^{0}, \\
\operatorname{Pr}\left(x_{12}+x_{22} \geq b_{2}\right) \gtrsim 0.8,
\end{gathered}
$$

where $x$ is nonnegative integer decision variable and demand $D$ is a normally distributed random variable with mean of 40 and 50 and variance of 49 and 64 . Thus, $F^{-1}(0.8)=46$ and $57, F^{-1}(0.5)=40$ and 50 . 
TABLE 3: Decision variable values.

\begin{tabular}{lcc}
\hline Supplier & Item & $X$ \\
\hline 1 & 1 & 0 \\
& 2 & 46 \\
\hline 2 & 1 & 0 \\
& 2 & 57 \\
\hline
\end{tabular}

The membership functions for three objectives are provided by which the total cost is minimized, the quality is maximized, and service is maximized. The linear (nonlinear) programming software LINDO/LINGO is used to solve this problem. We can then get the following objective function and constraints:

$$
\begin{aligned}
& \max \sum_{p=1}^{3} w_{j} \eta_{j}+\sum_{i=4}^{4} w_{i} \kappa_{i}, \\
& \eta_{p} \leq \mu_{f_{p}}(x) \\
& \kappa_{i} \leq \mu_{g_{i}}(x) \\
& 0.2 \leq w_{1} \leq 0.5 \\
& 0.1 \leq w_{2} \leq 0.4 \\
& 0.2 \leq w_{3} \leq 0.4, \\
& 0.15 \leq w_{4} \leq 0.5, \\
& w_{1}+w_{2}+w_{3}+w_{4}=1, \\
& x_{11} \leq 80, \quad x_{12} \leq 100, \\
& x_{21} \leq 90, \quad x_{22} \leq 80 .
\end{aligned}
$$

Our numerical example in Table 3 shows an interesting implication for supplier selection. It shows that unit cost does not always affect purchasing decision. This phenomenon is consistent with manager imagination. This result maybe means multiple criteria requirements should be met simultaneously. Because unit cost is not the sole criteria, decisions occasionally are not affected.

\section{Conclusion}

With the aggravation of competition, purchasing management is more and more significant. At the same time, supplier selection is one of the most important parts of procurement section. In practical conditions, it is a multiple objective decision problem in which the objectives and constraints are not equally important. In consideration of this situation, company must trade off all aspects for improving competitiveness.

However, much information is usually uncertain. For overcoming this difficulty, fuzzy theory and stochastic theory are two of the most suitable methods. Moreover, company often purchases many items from suppliers. Based on these situations, we develop a fuzzy multiobjective model for supplier selection under considering stochastic demand, different items, fuzzy objectives, constrains, and weight. The proposed model can effectively handle multiple items and uncertain information in supplier selection problem and help the manager to find out the appropriate suppliers. Meanwhile, our model can be transformed into a weighted max-min deterministic-crisp linear/nonlinear model. This transformation reduces computational complexity and makes the application of our method more understandable. Finally, from an application point of view, it is also worth further research about disruption risk in supplier selection problem.

\section{Conflict of Interests}

The authors declare that there is no conflict of interests regarding the publication of this paper.

\section{Acknowledgments}

This work is partially supported by grants from the National Science Foundation of China (NSFC nos. U1333115, 71373188, 71101060, 90924024, 91224001, 71231007, and 71101060), the Fundamental Research Funds for the Central Universities (no. 1101012), Post-1970 Young Scholars in Humanities and Social Sciences from Wuhan University, and Training Program of High Level International Journal Articles in Humanities and Social Sciences from Wuhan University.

\section{References}

[1] A. Ghobadian, A. Stainer, and T. Kiss, "A computerized vendor rating system," in Proceedings of the 1st International Symposium on Logistics, pp. 321-328, The University of Nottingham, Nottingham, UK, July 1993.

[2] C. A. Weber, J. R. Current, and W. C. Benton, "Vendor selection criteria and methods," European Journal of Operational Research, vol. 50, no. 1, pp. 2-18, 1991.

[3] S. Liu and L. Wang, "Understanding the impact of risks on performance in internal and outsourced information technology projects: the role of strategic importance," International Journal of Project Management, vol. 32, no. 8, pp. 1494-1510, 2014.

[4] W. Pan, X. Wang, Y.-G. Zhong et al., "A fuzzy multi-objective model for capacity allocation and pricing policy of provider in data communication service with different QoS levels," International Journal of Systems Science, vol. 43, no. 6, pp. 10541063, 2012.

[5] L. Wang, H. Qu, S. Liu, and C. Chen, "Optimizing the joint replenishment and channel coordination problem under supply chain environment using a simple and effective differential evolution algorithm," Discrete Dynamics in Nature and Society, vol. 2014, Article ID 709856, 12 pages, 2014.

[6] M. K. Luhandjula, "Fuzziness and randomness in an optimization framework," Fuzzy Sets and Systems, vol. 77, no. 3, pp. 291297, 1996

[7] M. K. Luhandjula, "Optimisation under hybrid uncertainty," Fuzzy Sets and Systems, vol. 146, no. 2, pp. 187-203, 2004.

[8] B. Liu, "Fuzzy random dependent-chance programming," IEEE Transactions on Fuzzy Systems, vol. 9, no. 5, pp. 721-726, 2001.

[9] B. Liu, "Fuzzy random chance-constrained programming," IEEE Transactions on Fuzzy Systems, vol. 9, no. 5, pp. 713-720, 2001. 
[10] B. Liu and Y.-K. Liu, "Expected value of fuzzy variable and fuzzy expected value models," IEEE Transactions on Fuzzy Systems, vol. 10, no. 4, pp. 445-450, 2002.

[11] Y.-K. Liu and B. Liu, "A class of fuzzy random optimization: expected value models," Information Sciences, vol. 155, no. 1-2, pp. 89-102, 2003.

[12] M. Kumar, P. Vrat, and R. Shankar, "A fuzzy programming approach for vendor selection problem in a supply chain," International Journal of Production Economics, vol. 101, no. 2, pp. 273-285, 2006.

[13] A. Amid, S. H. Ghodsypour, and C. O’Brien, "Fuzzy multiobjective linear model for supplier selection in a supply chain," International Journal of Production Economics, vol. 104, no. 2, pp. 394-407, 2006.

[14] A. Amid, S. H. Ghodsypour, and C. O’Brien, "A weighted additive fuzzy multiobjective model for the supplier selection problem under price breaks in a supply Chain," International Journal of Production Economics, vol. 121, no. 2, pp. 323-332, 2009.

[15] D. D. Wu, Y. Zhang, and D. L. Olson, "Fuzzy multi-objective programming for supplier selection and risk modeling: a possibility approach," European Journal of Operational Research, vol. 200, no. 3, pp. 774-787, 2010.

[16] B. A. Ozkok and F. Tiryaki, "A compensatory fuzzy approach to multi-objective linear supplier selection problem with multipleitem," Expert Systems with Applications, vol. 38, no. 9, pp. 1136311368, 2011.

[17] R.-H. Lin, "An integrated model for supplier selection under a fuzzy situation," International Journal of Production Economics, vol. 138, no. 1, pp. 55-61, 2012.

[18] S. Nazari-Shirkouhi, H. Shakouri, B. Javadi, and A. Keramati, "Supplier selection and order allocation problem using a two-phase fuzzy multi-objective linear programming," Applied Mathematical Modelling, vol. 37, no. 22, pp. 9308-9323, 2013.

[19] H. S. Kilic, "An integrated approach for supplier selection in multi-item/multi-supplier environment," Applied Mathematical Modelling, vol. 37, no. 14-15, pp. 7752-7763, 2013.

[20] D. Choudhary and R. Shankar, "A goal programming model for joint decision making of inventory lot-size, supplier selection and carrier selection," Computers and Industrial Engineering, vol. 71, no. 1, pp. 1-9, 2014.

[21] W. Pan, L. Yu, S. Wang, and X. Wang, "A fuzzy multi-objective model for provider selection in data communication services with different QoS levels," International Journal of Production Economics, vol. 147, pp. 689-696, 2014.

[22] L. A. Zadeh, "Fuzzy sets," Information and Computation, vol. 8, pp. 338-353, 1965.

[23] J. J. Buckley, "Fuzzy hierarchical analysis," Fuzzy Sets and Systems, vol. 17, no. 3, pp. 233-247, 1985.

[24] A. Kaufmann and M. M. Gupta, Introduction to Fuzzy Arithmetic: Theory and Applications, D. Van Nostrand Reinhold Company, New York, NY, USA, 1991.

[25] D. S. Negi, Fuzzy analysis and optimization [Ph.D. Dissertation], Department of Industrial Engineering, Kansas State University, 1989.

[26] L. A. Zadeh, "The concept of a linguistic variable and its application to approximate reasoning-II," Information Sciences, vol. 8, no. 4, pp. 301-357, 1975.

[27] H.-J. Zimmermann, "Fuzzy programming and linear programming with several objective functions," Fuzzy Sets and Systems, vol. 1, no. 1, pp. 45-55, 1978.
[28] H. J. Zimmermann, Fuzzy Sets, Decision Making and Expert Systems, Kluwer Academic Publishers, Boston, Tex, USA, 1987.

[29] M. Sakawa, Fuzzy Sets and Interactive Multiobjective Optimization, Plenum Press, New York, NY, USA, 1993.

[30] H. J. Zimmermann, Fuzzy Set Theory and Its Applications, Kluwer Academic Publishers, Boston, Mass, USA, 4th edition, 1992.

[31] R. E. Bellman and L. A. Zadeh, "Decision-making in a fuzzy environment," Management Science, vol. 17, no. 4, pp. B141-B164, 1970.

[32] R. N. Tiwari, S. Dharmahr, and J. R. Rao, "Fuzzy goal programming - an additive model," Fuzzy Sets and Systems, vol. 24, no. 1, pp. 27-34, 1987. 


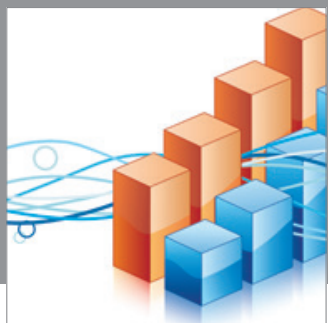

Advances in

Operations Research

mansans

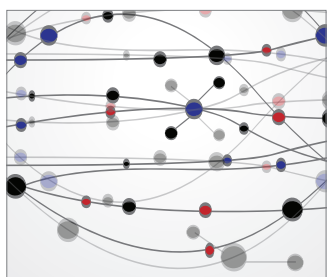

The Scientific World Journal
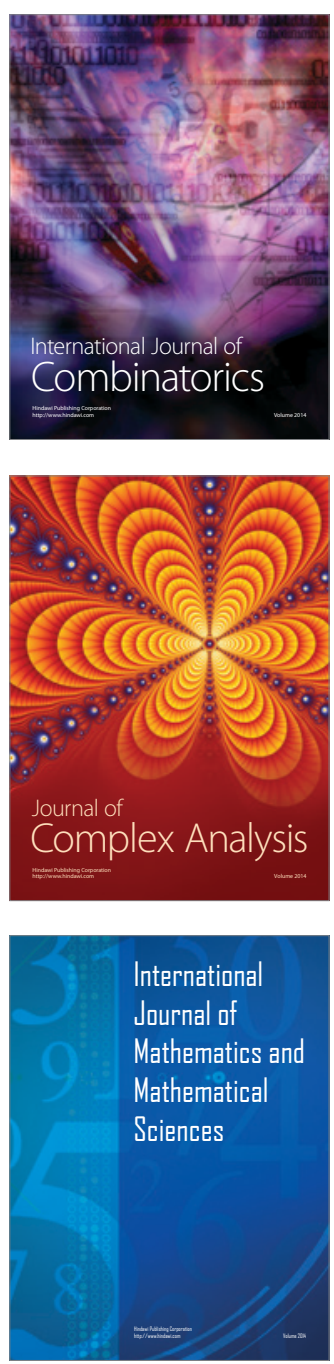
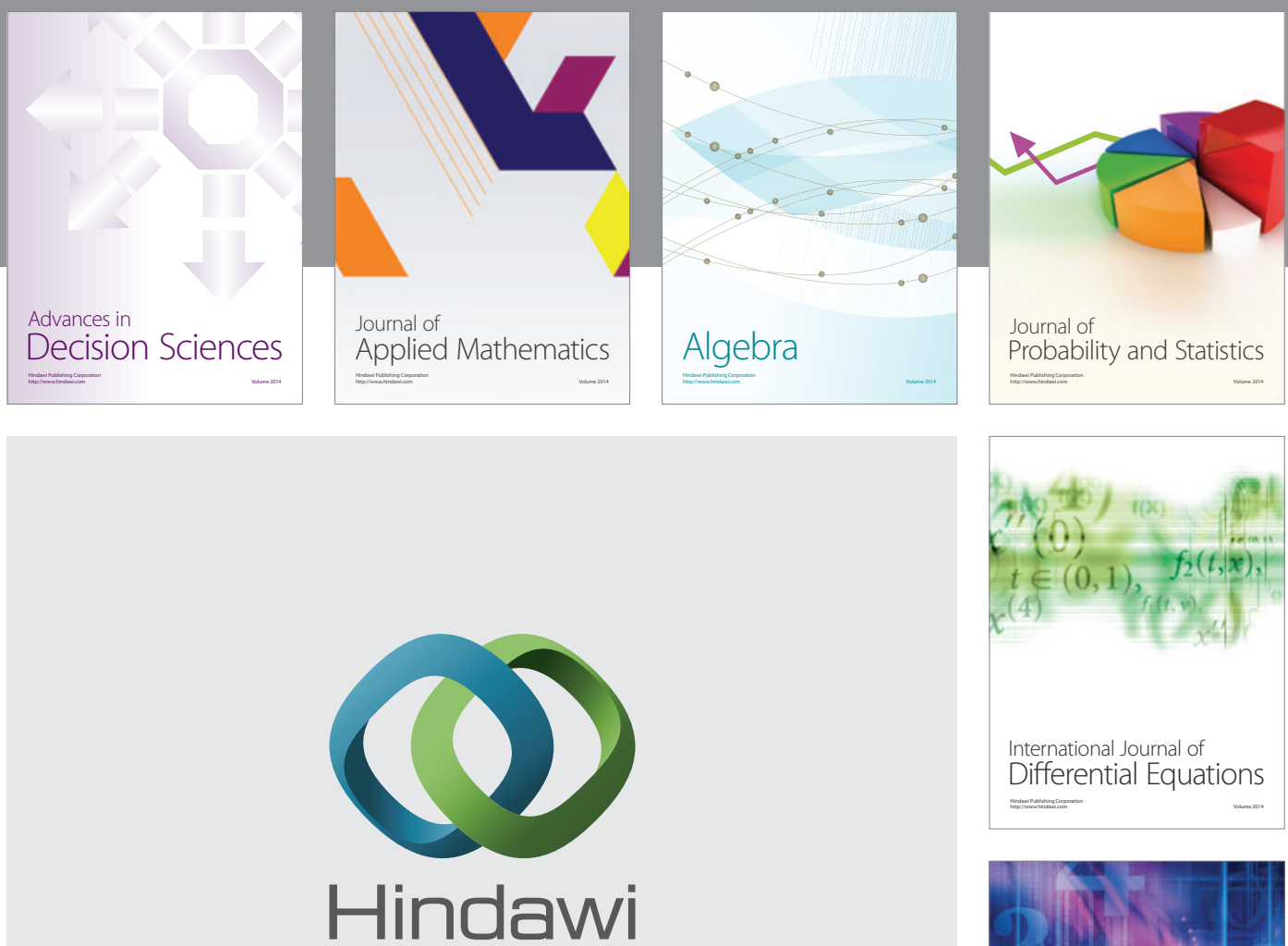

Submit your manuscripts at http://www.hindawi.com
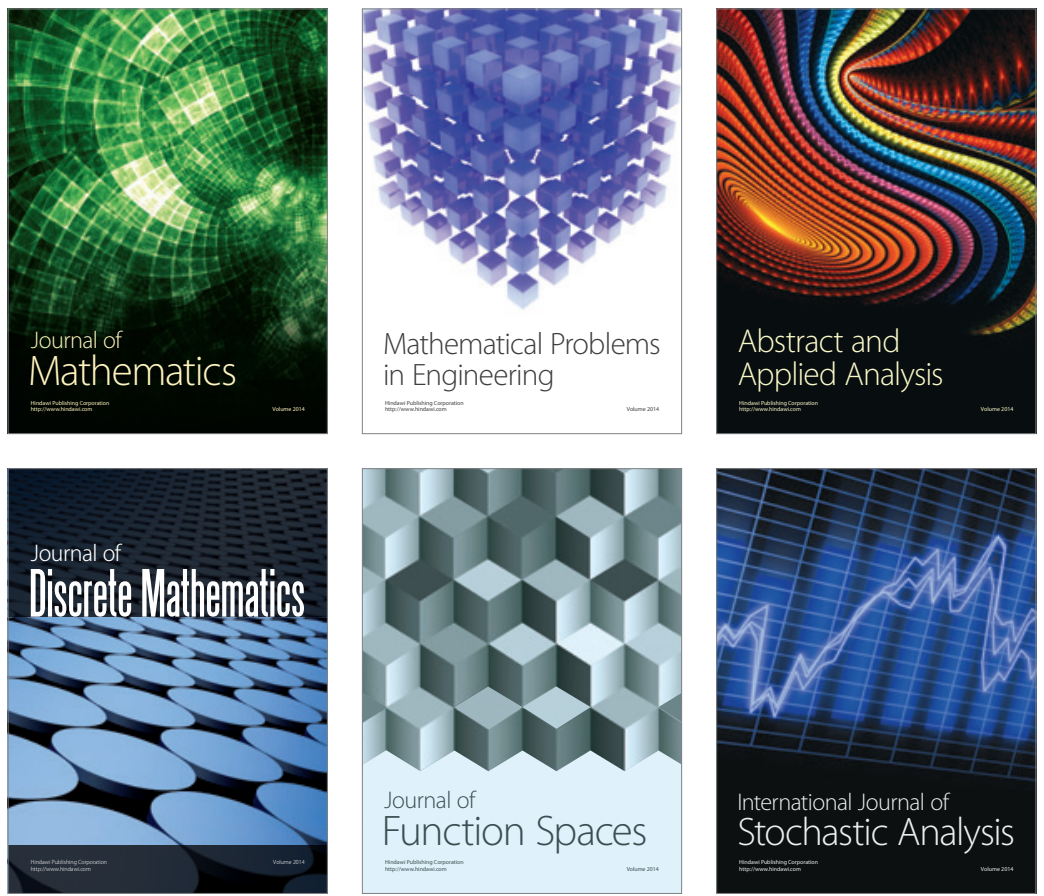

Journal of

Function Spaces

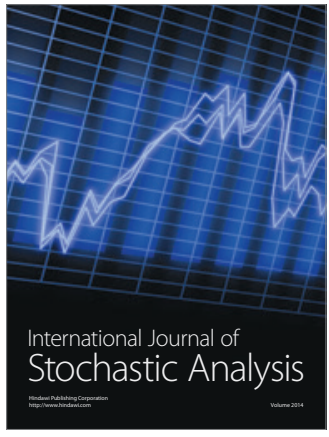

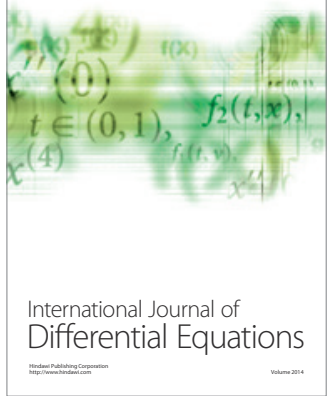
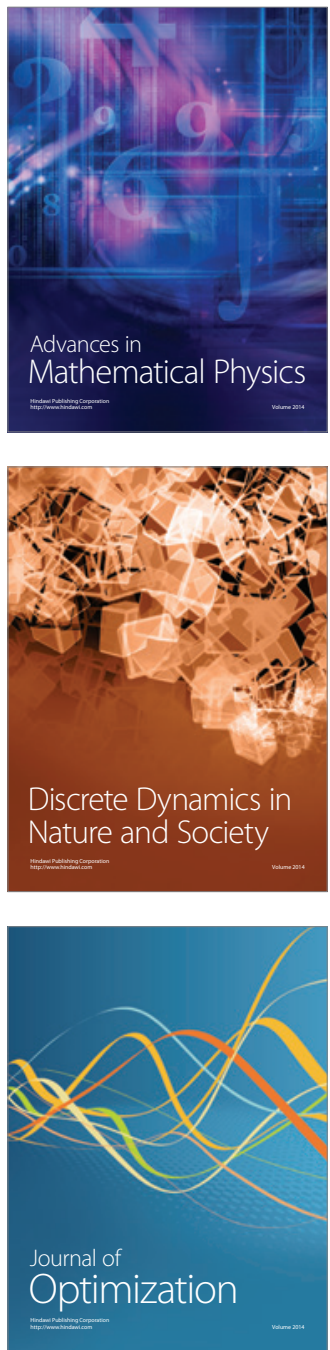